\title{
The preference of albino rats for free or response-produced food*
}

\author{
GILBERT ATNIP and DAVID HOTHERSALL \\ The Ohio State Lniversitu. Columbus. Ohio 43210
}

Albino rats were trained to free-feed in an operant chamber and then to leverpress for food. Subsequently, they were tested for a preference between continuing to leverpress for food on CRF, FR 2, and FR 10 schedules or eating free food. Five of the seven rats showed a preference for free food, which strengthened on schedules requiring more than one response to produce a food pellet. The results reduce the possibility that the difference between findings of prior studies of food preferences is due to strain differences in the rats used as Ss.

Carder \& Berkowitz (1970) gave rats a choice between leverpressing for food or eating freely available food pellets. When CRF and FR 2 schedules were in effect, their rats consistently leverpressed for most of the pellets they ate. Only when the number of responses for each pellet was increased to 10 (FR 10) did the preference for response-produced food weaken. Similar results have been reported for pigeons by Neuringer (1969, 1970) and for rats and children by Singh (1970). Singh (1972) interpreted such findings as showing the dominance of the "Protestant ethic" over the "welfare ethic" as a determinant of behavior.

Not all studies, however, have found a preference for response-produced over free food. Koffer \& Coulson (1970) reported that cats. given choice between working for fish or getting it free. consistently chose the free food. Taylor (1972) found that rats preferred to consume both free food and water rather than to leverpress for either. Lambe \& Guy (1973) found that both rats and gerbils consistently preferred free over earned food. Hothersall, Huey, \& Thatcher (1973) used the procedure described by Carder \& Berkowitz (1970) in three experiments in which different methods of free food presentation were employed. In all three experiments, the majority of the rats tested showed a preference for free over response-produced food. One possible explanation of the difference between these results and those of Carder \& Berkowitz (1970) is that Hothersall et al used hooded rats, whereas Carder and Berkowitz used albinos. In the present experiment, the preferences of albino rats for either free or response-produced food were investigated using a procedure similar to that of Carder \& Berkowitz (1970).

\section{METHOD}

Subjects

The Ss were eight naive male albino rats. approximately 90 day's old at the beginning of the experiment. One $\mathrm{S}$ died during

\footnotetext{
* Requests for reprints should be sent to David Hothersall, Laboratory of Comparative and Phrsiological Psychology. The Ohio State University Research Center. 1314 Kinnear Road, Columbus, Ohio 43212 .
}

the course of the study, and so data are reported for the remaining seven Ss.

\section{Apparatus}

The apparatus consisted of two standard operant conditioning chambers housed inside sound-attenuating research chests. Each chest was equipped with an exhaust fan. which also provided masking noise during the sessions. The only light during the sessions came from the overhead light in the experimental room. Two metal dishes, $7.9 \mathrm{~cm}$ in diam and $4.0 \mathrm{~cm}$ deep, were used to present free food during preference-testing sessions. Standard relay programming and data-recording equipment were located in a room adjacent to the experimental room.

\section{Procedure}

The study was conducted as two replications with four Ss in each. The procedures were identical for each replication and were similar to those employed by Carder \& Berkowitz (1970) and by Hothersall et al (1973). The rats were first food-deprived for $24 \mathrm{~h}$. Then, on each of the first 3 experimental days, they were placed individually in the operant conditioning chambers with free food (300 45-mg Noyes pellets) present. Leverpresses were not reinforced during these sessions. The number of free food pellets eaten was recorded. The remaining 18 days of the study were as follows: 6 days of leverpressing on a CRF schedule, 2 days of preference testing on CRF, 2 days of leverpressing on an FR 2 schedule, 2 days of preference testing on FR 2, 2 days of leverpressing on FR 10,2 days of preference testing on FR 10 . and finally 2 days of preference testing on CRF. Leverpressing sessions were $75 \mathrm{~min}$ long, with Noyes 45 -mg pellets as reinforcers. No magazine training or shaping was employed. On preference-testing days, free food (300 pellets) was introduced into the chamber after 25 responses had been emitted on CRF and after 50 responses had been emitted on FR 2 and FR 10. Preference-testing sessions were $1 \mathrm{~h}$ long. After each such session. the number of free food pellets eaten was recorded.

Sessions were run 6 days per week, Monday through Saturday. Ss were fed Purina Lab Chow on Sunday; other than this feeding, they received all their food during experimental sessions. Ad lib water was available in the home cages at all times.

\section{RESULTS}

The total number of pellets eaten (from the free-food dish and obtained by leverpressing) after the introduction of free food was determined for each preference-testing session. The ratio of free food pellets eaten to total pellets eaten was then determined and converted to a percentage. A mean percentage for the two testing sessions on each schedule was computed for each $\mathrm{S}$. These means were ranked and are shown in Table 1.

Five of the seven rats showed a preference for free food under all schedules, with three exceptions: Rat J4 on FR 2 and CRF retest. and Rat J3 on CRF retest. Two of the rats showed a preference for leverpressing until the schedule became FR 10. upon which they began to prefer the free food. They returned to their former preference on the CRF retest.

With regard to the three exceptions to free-food preference mentioned above. it is noteworthy that in two of these cases, J4 on FR 2 and J3 on CRF retest. a 
Table 1

Percentage of Total Pellets Eaten that Were Free Food Pellets

\begin{tabular}{ccccc}
\hline S & CRF & FR 2 & FR 10 & CRF \\
\hline F5 & 94 & 91 & 93 & 88 \\
J4 & 92 & 44 & 70 & 45 \\
J2 & 78 & 74 & 81 & 78 \\
J3 & 63 & 66 & 75 & 46 \\
F6 & 60 & 75 & 97 & 50 \\
F7 & 8 & 6 & 58 & 4 \\
J1 & 6 & 17 & 55 & 3 \\
\hline
\end{tabular}

large number of free food pellets (224 and 197. respectively) were spilled by the rat in one of the test sessions. The fact that the rat could not eat these spilled pellets probably accounts for the lowered mean percentages in these cases. The precentages for those sessions in which no pellets were spilled were $62 \%$ for $\mathrm{J} 4$ on $\mathrm{FR} 2$ and $78 \%$ for $\mathrm{J} 3$ on $\mathrm{CRF}$ retest.

During the course of the study, all 300 of the free food pellets were eaten during 15 of the 56 preference-test sessions. The group mean numbers of free food pellets eaten during the free-food tests were: 176 pellets on CRF, 178 on FR 2. 231 on FR 10, and 155 on CRF retest.

\section{DISCUSSION}

The results of this study are in agreement with the results of Hothersall et al (1973). A majority of rats (five out of seven in this experiment) preferred free food to response-produced food in most cases. This result tends to rule out the possibility that the difference in preference findings obtained by Hothersall et al (1973) and by Carder \& Berkowitz (1970) is due to the difference between the strains of rats used in those studies. The former study used hooded rats and found a preference for free food. while the latter used albino rats and found a preference for earned food. The present study also used albino rats, but found a preference for free food. Furthermore, Taylor (1972), using a somewhat different procedure from that of the present study. tested albino rats and found that they preferred free food. It seems unlikely. therefore. that there is a difference between hooded and albino rats in regard to preference for free or earned food. The disparity in results between Carder and Berkowitz and Hothersall et al is most likely due to some factor other than strain of rat.

One question which is raised by the results of Hothersall et al (1973) and the present study is, why do rats that prefer free food leverpress at all after free food is introduced? In other words. why are the percentages of free food eaten less than $100 ?$ ? Observations during the test sessions in this study showed that. for rats that preferred free food, a long period of time generally passed between the introduction of free food and the resumption of leverpressing. Once resumed, leverpressing gernerally continued until the end of the session. For rats that preferred earned food. on the other hand, there was generally a relatively short latency before the resumption of leverpressing after the introduction of free food. In the second replication of this study, latencies were timed for both of the FR 2 test sessions and one of the FR 10 test sessions. The mean latencies to resume barpressing after the introduction of free food for all three sesions were: $39.7 \mathrm{~min}$ for Rat $15.37 \mathrm{~min}$ for $\mathrm{F} 6$, and $4.3 \mathrm{~min}$ for $\mathrm{F} 7$. These latency observations. coupled with the fact that the rats tended to eat approximately the same number of pellets in each session. suggest that rats that preferred free food generally ate a large number of the available free food pellets and then resumed leverpressing to earn the remainder of their daily "ration." It is possible that leverpressing would not have resumed had there been 400 or 500 free food pellets available. rather than 300 .

Another question is raised by the fact that. in both the Hothersall et al (1973) study and this experiment. approximately $25^{\circ}$, of the rats tested showed a preference for earned over free food. There is no evidence to suggest a reason for the difference between these rats and those that preferred free food. It might be noted at this point. however, that the "free" food in these studies was not really "free." in the sense that the rat could obtain it with no effort. In order to eat the "free" pellets, the rat had to climb onto the side of the free-food dish and lean down into the dish to get the pellets. It is possible that. in terms of effort. this task is more demanding for some rats than is leverpressing. Such rats would be expected to show a preference for leverpressing over free feeding. Also. if the effort required for obtaining free pellets increases as the number of pellets left in the dish decreases, it would be reasonable to expect some animals to stop eating free food before all 300 pellets were consumed, and to resume leverpressing. This was indeed found to be true for some of the rats that preferred free food.

It is clear that the question of why some animals prefer earned to free food remains unanswered. It seems likely that the question cannot be answered adequately within the confines of experiments similar to the present study. but that new experimental methods will be required for its solution. What is clear from the results of this study, as well as those of Taylor (1972). Lambe \& Guy (1973), and Hothersall et al (1973), is that the generalization that rats prefer earned over free food was premature.

\section{REFERENCES}

Carder, B., \& Berkowitz, K. Rats' preference for earned in comparison with free food. Science, 1970, 167, 1273-1274.

Hothersall, D., Huey, D., \& Thatcher, K. The preference of rats for free or response-produced food. Animal Learning \& Behavior, 1973, in press.

Koffer, K. \& Coulson, G. Feline indolence: Cats prefer free to response-produced food. Psychonomic Science, 1971, 24, 41-42.

Lambe, D. R., \& Guy, E. G. A comparison of the preference for free vs earned food in rats and mongolian gerbils. Proceedings of The Ohio Academy of Science. April 1973.

Neuringer, A. J. Animals respond for food in the presence of free food. Science, $1969,166,399-401$.

Neuringer, A. J. Many responses per food reward with free food present. Science, 1970, 169, 503-504.

Singh, D. Preference for bar-pressing to obtain reward over free-loading in rats and children. Journal of Comparative \& Physiological Psychology, 1970, 73, 320-327.

Singh, D. The Pied Piper vs the Protestant Ethic. Psychology Today, $1972,5,53-56$

Taylor, G. T. A limitation of the contrafreeloading phenomenon. Psychonomic Science, 1972, 29, 173-174.

(Received for publication June 11, 1973.) 